\title{
MODELLING OF COMBUSTION PROCESSES OF LIQUID FUELS
}

\author{
Antoni Jankowski \\ Air Force Institute of Technology \\ 6 Ksiecia Boleslawa Street, 01-494 Warsaw, Poland \\ tel.: +4822 6851101, fax: +4822836447 \\ e-mail:jankoa@itwl.pl
}

\begin{abstract}
The modelling of combustion processes of liquid fuels assumes that combustion processes of fuels always occur in gas-phase, gas-phase may be homogeneous or heterogeneous mixture. For homogeneous mixture, course of combustion processes is controlled by kinetics of chemical reactions. For heterogeneous mixture, course of combustion processes is controlled by initial processes, with reference to liquid fuels, vaporization processes of fuel occur. Flow of combustion gases (velocity and kind) intensifies combustion processes, influence of pressure on combustion processes of liquid fuels differs from the influence on combustion processes of gas fuels.

The subject of the paper is the modelling of the combustion process of heterogeneous fuels, researches processes of spraying and combustion. The researches of atomization and combustion processes were performed in combustion chamber of the constant volume. To carry out the research, the test equipment was used, which allowed the visualization of atomization and combustion processes by means of the camera to high-speed photographing, measurements of distribution velocity stream atomised fuel with the laser-equipment PIV, LDV and PDPA, and measurement of the pressure in combustion chamber. The model of the combustion process of heterogeneous fuels based on properties of the boundary layer with addition of the mass was worked out.
\end{abstract}

Keywords: combustion engines, combustion processes, liquid fuel combustion, boundary layer, modelling

\section{Introduction}

The emission of harmful components of combustion gas and the fuel consumption have critical influence on the development of piston-combustion engines, both of the spark-ignition (SI) and of the self-ignition (CI), as well as turbines. With reference to the fuel consumption and the emission of harmful gases, the most important is to secure the suitable dosage of fuel and its best use to accomplish the effective work. Therefore, the growing interest of the use of the direct-injection to combustion chamber in piston engines is observed.

In the initial development period of piston engines it was realized that the more effective work of engines one could obtain when the throttle is not used in the engine. In that manner, losses of pumping can be eliminated and the improvement process of refilling the cylinders can take place. Tendencies within the trend range of piston engines construction go towards the direct-injection in engines SI and CI. The usage of the combustion of the homogeneous load, so called HCCI system - Homogeneous Charge Compression Ignition is the subject of many works. HCCI engines allow obtaining the efficiencies comparable with the ones of compression-ignition engines, but their defect is the comparatively low density of energy.

With reference to SI engines, the dominant are the engines of the injection to inlet channels, and to CI engines - engines of the direct-injection. The comparison of presently manufactured SI and CI engines, which are applied to propulsion of vehicles, shows that CI engines are characterized with lower values of the specific fuel consumption, so they are more economic than SI engines with the fuel injection to inlet channels, so called PFI (Ports Fuel Injection). This is an effect of the use of higher compression ratio, connected with the elimination of the choke of throttle. However, CI engines are characterized with the somewhat greater noise level, with the lower range of rotational engine speed, with the lower stability and the higher emission of particulate matters and $\mathrm{NO}_{x}$. 


\section{Modelling of combustion processes}

The combustion speed is determined by such process, which is the slowest. In the situation of the combustion of uniform homogeneous mixtures of fuel-oxidant (air), this process is kinetics of chemical reactions. However in case of heterogeneous mixtures such processes are physical processes, vaporisation and the mixing. The model of the combustion process of heterogeneous mixtures, in which an assumption was made that there is a mutual interaction of the phase gaseous and liquid and processes controlling the combustion are the slowest processes, was worked out. With reference to liquid fuels, the slowest process is decomposition process of the liquid phase. Combustion processes of liquid fuels are relative to boundary layer, which then is relative to the speed and the character of the flow of the stream of gases. The flow can be laminar, transient or turbulent. The speed of the stream of gases intensifies combustion processes. The speed and the kind of the stream of gases influence the thickness of boundary layer. The influence of pressure on combustion processes of liquid fuels multiples, and is connected with the influence of the speed of the stream of gases, and is dependant on the kind of the fuel. The increase in pressure intensifies combustion processes in phase gaseous, but at the same time decreases intensity decomposition of the liquid phase, which controls the combustion. The increase in pressure causes decreasing of the distance to the flame front from surface of the fuel, which increases the heat stream delivered to surface of the fuel and intensifies decomposition process (vaporization) of the fuel. The intensification decomposition process of the fuel connected with pressure increase moves away the flame front from surface of the fuel. In these three situations as a result the opposed influence of the pressure and decomposition of the liquid phase can appear. The flame front can decrease distance, increase distance or to stay in the same distance to surface of the liquid fuel. The majority of previous models concerning the combustion of liquid fuels assumed that the fuel was homogeneous, the combustion has a constant character, the temperature on border surface of phases is boiling temperature of liquid. The influence of the radiation, diffusion, changes of pressure, changes of physical characteristics and chemical fuel, air and exhaust gases were neglected. Two situations: the combustion under conditions of the lack of the convection and conditioned appearances of the convection can be distinguished.

Image phenomena appearing in combustion of liquid fuels is the boundary-layer with perpendiculars to surface of the separation of phases with mass addition. Equation of heat balance for the single droplet under conditions of described is dependence (1):

$$
r_{c}^{2} \frac{d}{d r}\left(\lambda \frac{d T}{d r_{c}}\right)+2 r_{c} \lambda \frac{d T}{d r_{c}}-\frac{\dot{m} h_{l}}{4 \pi} \frac{d\left(c_{p g} T\right)}{d r_{c}}=0 .
$$

At assumption constant value of the $\mathrm{c}_{\mathrm{pg}}$, the dependence on the temperature distribution in gas phase of the combustion zone has a form (2):

$$
\frac{T_{f}-T}{T_{f}-T_{0}}=\frac{\exp \left(-\frac{\dot{m} c_{p g}}{4 \pi \lambda \lambda_{0}} \frac{r_{c}}{r_{f}}\right)-\exp \left(-\frac{\dot{m} c_{p g}}{4 \pi \lambda \lambda_{0}} \frac{r_{c}}{r}\right)}{\exp \left(-\frac{\dot{m} c_{p g}}{4 \pi \lambda l_{b}} \frac{r_{c}}{r_{f}}\right)-\exp \left(-\frac{\dot{m} c_{p g}}{4 \pi \lambda \lambda_{0}}\right)} .
$$

At assumption that in the liquid phase appears no chemical reactions, the balance of energy is described by the equalization (3):

$$
\dot{m} h_{c}=4 \pi \lambda r_{c}\left(\frac{d T}{d r_{c}}\right)
$$

Solution of equations (2) and (3) gives for mass-rate of the droplet combustion (4):

$$
\dot{m}=\frac{4 \pi r \lambda}{c_{p g}\left(r_{f}-r\right)} \ln \left[1+\frac{\lambda_{c} c_{p g}}{\lambda h}\left(T_{f}-T_{c}\right)\right] \text {. }
$$

The equation (5) represents the linear speed of the surface displacement of the drop of the fuel 
depending on the speed of gases, the pressure, the kind of the fuel, the temperature of the flame, the heat value, physical characteristics and chemical of the stream of gases with reference to the laminar flow.

$$
l_{l}=l_{b}+0.2 \psi_{l} \operatorname{Pr}^{-0,67}\left(\frac{\mu_{g}}{R_{g} T_{f}}\right)^{0.5} c_{p g} \frac{T_{f}-T_{0}}{\rho_{c}\left[c_{c}\left(T_{c}-T_{\infty}\right)-Q_{c}\right]}\left(\frac{v p}{d}\right)^{0,5} \text { for } \quad R e_{d}<R e_{d c r} .
$$

The equation (6) represents the linear speed of the displacement surface of the drop of the fuel depending on the speed of gases, the pressure, the kind of the fuel, the temperature of the flame, the heat value, physical characteristics and chemical of the stream of gases in reference to the turbulent flow.

$$
l_{t}=l_{b}+0.03 \psi_{t} \operatorname{Pr}^{-0.67} \frac{\mu_{g}^{0.2}}{\left(R_{g} T_{f}\right)^{0.8}} c_{p g} \frac{T_{f}-T_{0}}{\rho_{c}\left[c_{c}\left(T_{c}-T_{\infty}\right)-Q_{s}\right]} \frac{(v p)^{0.8}}{d^{0.2}} \text { for } R e_{d}>R e_{d c r} .
$$

The speed decomposition liquid phases under conditions of the lack of the convection one can define from the well-known dependence (7) for the speed of the combustion of the drop of the fuel. It is worth to underline that constant speed of the combustion of the drop is in the narrow range and approximately value at the combustion of the drop in air is approximately $10^{-6} \mathrm{~m}^{2} / \mathrm{s}$.

$$
d_{b}^{2}=d_{0}^{2}-k t .
$$

The thickness of boundary layer $\sigma$ is defined with reference to the laminar flow as result of solution of equations of the boundary layer and is described by dependence (8):

$$
\sigma_{l}=5 \operatorname{Re}_{d}^{-0.5} \operatorname{Pr}^{-0.33} d, \quad \text { for } \quad \operatorname{Re}_{d}<R e_{d c r} .
$$

The thickness of boundary layer $\sigma$ with reference to the flow turbulent is defined on the basis of Prandtl hypotheses on the universal profile of the speed, from the equation (9):

$$
\sigma_{t}=33 \operatorname{Re}_{d}^{-0.8} \operatorname{Pr}^{-0.33} d, \quad \text { for } \operatorname{Re}_{d}>\operatorname{Re}_{\text {dcr }} .
$$

where:

$l \quad$ - linear rate of the surface displacement of the separation of phases;

$l_{b}-$ decomposition rate of liquid phase which is defined under conditions of absence convection from equation (7);

$\lambda-$ coefficient of thermal conductivity;

$\lambda_{c}-$ coefficient of fuel thermal conductivity;

$h_{s}$ - decomposition heat of liquid;

$T_{f}$ - temperature of front flame;

$T_{c}$ - temperature of surface of phases' separation;

$r_{c}$ - radius of fuel droplet;

$r_{o}$ - linear rate of displacement of surface of phases separation in convection absent;

$r_{f}$ - radius of burn zone in convection absent;

$T_{c}$ - temperature of surface of phases separation;

$\psi$ - coefficient defining degree decreasing of the stream heat caused with addition mass from flowed burned surface;

$P r$ - Prandt' number;

$\dot{m}$ - mass-rate of stream of liquid phase decomposition;

$M$-dynamic viscidity coefficient;

$R_{g}$ - gas constant;

$T$ - temperature;

$c_{p g}$ - specific heat capacity at constant pressure;

$\rho$ - density;

$c_{c}$ - specific heat of liquid;

$Q$ - heat of decomposition; 
$v$ - velocity vector component;

$p$ - pressure;

$d$ - drop diameter;

$R e_{d}$-Reynolds' Number referred to drop diameter;

$k-$ constant defining linear decomposition rate of liquid phase;

$t \quad$ - time;

$\sigma \quad$ - thickness of boundary layer.

Indexes: $l, t$-the laminar flow bears upon, turbulent, respectively, $g$ - the gaseous phase, $c$ - the liquid phase,$d$ - the diameter of the drop, $f$-flame front, 0 -refers to drop inside the , $\infty-$ environments.

The carried out measurement of the parietal thickness of layer under conditions of model at applying of the laser-equipment LDV PDPA showed that the close relationship existed between thickness of boundary layer and with the combustion rate of liquid fuels, washed with the stream of gases.

Model considers processes occurring in liquid and gas phase particularly heterogeneous processes decomposition individual phase components, as and processes occurring in gas phase which affect processes decomposition of the liquid phase. These processes refer to real conditions, when combustion appears in combustion chamber, at the fuel injection to the combustion chamber, when appears intensive relative to gases movement of droplets. Droplets, due to heavy inertia with reference to gas stream, are not carried off by the gas stream, especially with reference to turbulent flow, large velocity differences of the gas stream and droplets occur. If decomposition rate of droplets from liquid to gas phase is less than combustion rate, flame quenching takes place. However both own observations, as and other authors show that the combustion rate can be indeed intensified at occurring turbulent stimulation of the gas stream in the combustion chamber.

\section{Researches process atomising and combustion}

The researches of atomising and combustion processes were performed in combustion chamber of the constant volume. To carry out the research, the test equipment were used making possible the visualization process atomising and combustion by means of the camera to high-speed photographing, measurements distribution of the speed of the stream atomised fuel with the laserequipment PIV, LDV and PDPA and measurement pressure in combustion chamber of constant volume. Example-results distribution of the speed by means of PIV shows Fig. 1.
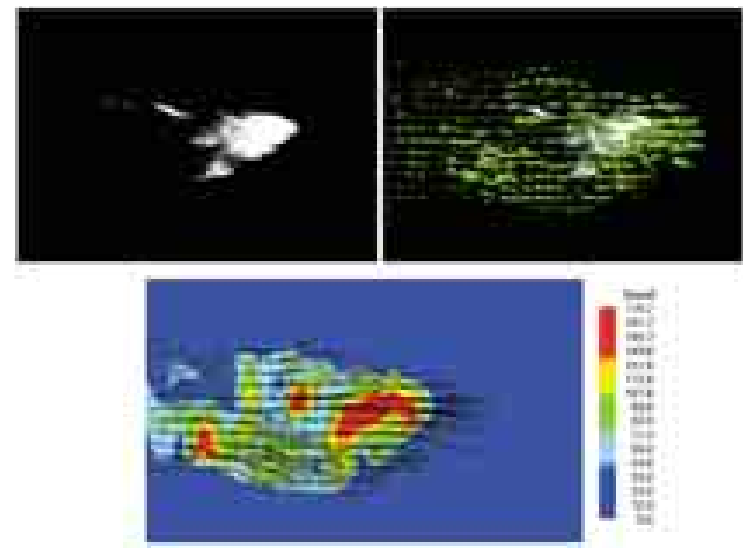

Fig. 1. PIV velocity field for liquid fuel spray

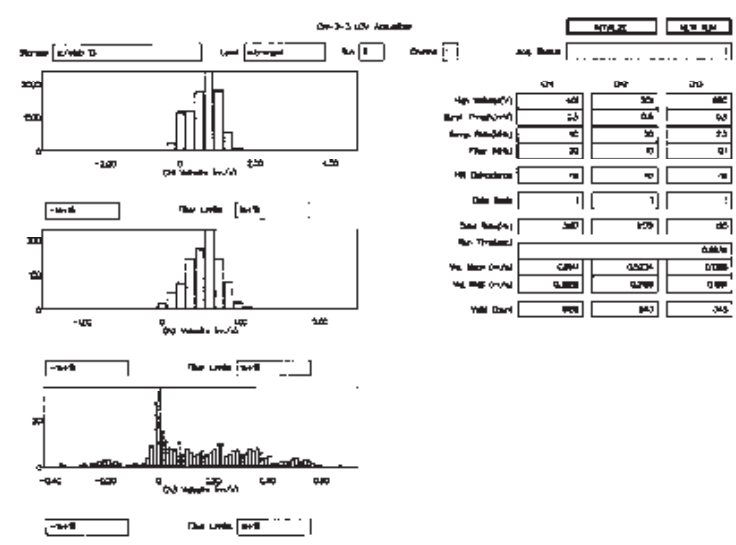

Fig. 2. LDV-PDPA velocity field

Area of the speed of the stream atomised fuel by means of the laser-equipment LDV-PDPA shows Fig. 2.

Fig. 3 shows linear, volumetric distribution and Rosin-Rammler dependence that became received by means of the laser-apparatus LDV-PDPA. 
Fig. 4 shows pressure course of liquid fuel combustion process in constant volume chamber obtained by means of equipment Kistler.

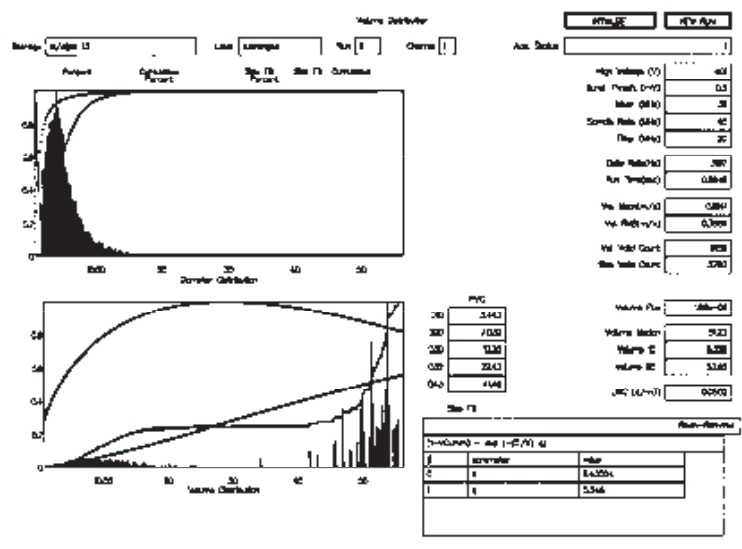

Fig. 3. Linear, volumetric distribution and RosinRammler dependence

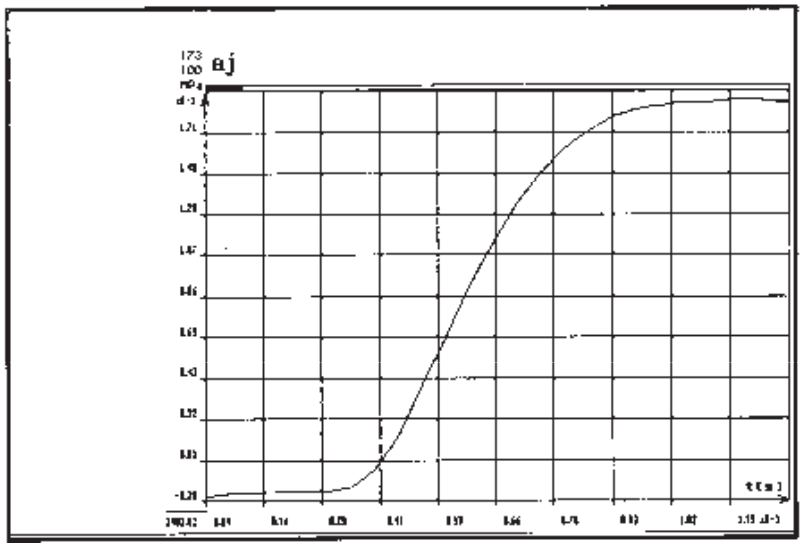

Fig. 4. Pressure course of liquid fuel combustion process in constant volume chamber

Fig. 5 shows cross-section of burnt stripe of solid fuel in comparison to photo of thermal boundary layer of combustion solid fuel stripe obtained with high-speed camera.

Fig. 6 shows the comparison of burnt of stripe cross-section and the boundary layer obtained from the data, which are shown in Fig. 5.
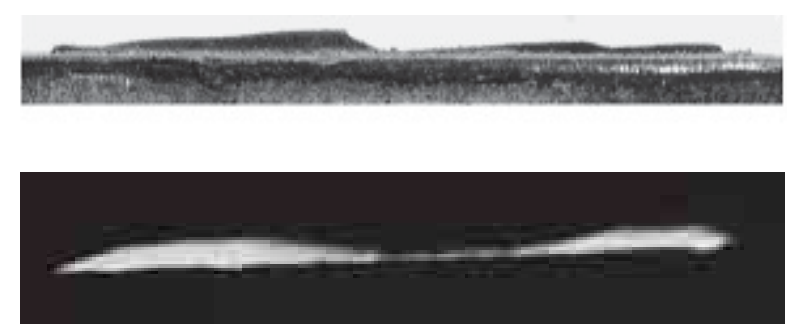

Fig. 5. Cross-section of burnt stripe of solid fuel in comparison to cross-section of the thermal boundary layer for burnt fuel stripe

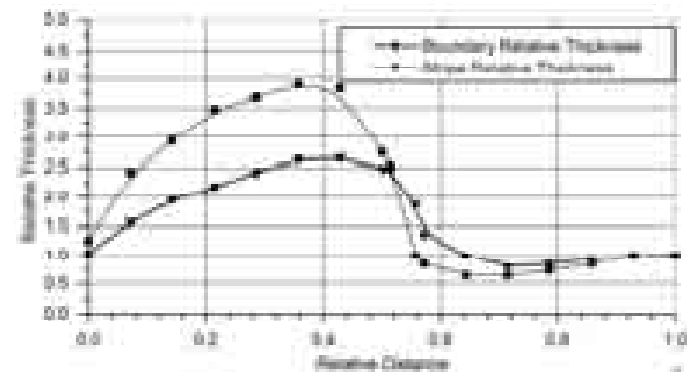

Fig. 6. The comparison of burnt of stripe cross-section and the boundary-layer versus relative distance

\section{Conclusions}

- Combustion rate at occurring of convection, velocity components of gases of liquid fuels changes combustion processes of these fuels.

- Increasing of velocity of the gas stream always increases the combustion rate, whereat the character of the influence is relative to the kind of the flow, which can be laminar, transient or turbulent.

- The pressure influences additionally on the velocity component of combustion rate, whereat this influence is different and depends mostly on the kind and the fuel parameters.

- Fundamentally, pressure increasing increases the velocity component of combustion rate.

- The pressure influences additionally on the speed component of the speed of the combustion, whereat this influence is different and depends mostly from the kind and characteristics of the fuel.

- However with reference to some fuels, with the pressure increasing, absence of the pressure influence or even rate combustion reduction can occur.

- The essential influence on the combustion process has a kind movement of combustion gases and the turbulence magnitude, and first of all the kind and thickness of the boundary-layer.

- Generally, on combustion rate of liquid fuels, the essential influence has a kind (laminar, 
transient or turbulent) and the thickness of the thermal boundary-layer around the fuel droplet.

- Performed photographs of the boundary-layer confirm assumptions on the principle influence of the thickness and the kind of the boundary-layer on combustion processes of liquid fuels.

\section{References}

[1] Apte, S., Yang, V., An LES Study of Transition and Flow Instability in a Porous-Walled Chamber with Mass Injection, Journal of Fluid Mechanics, Vol. 477, pp. 215-225, 2003.

[2] Jankowska-Sieminska, B., Jankowski, A., Slezak, M., Analysis and research of piston working conditions of combustion engine in high thermal load conditions, Journal of KONES 2007, Vol. 14, No. 3, pp. 233-234, Warsaw 2007.

[3] Jankowski, A., Czerwinski, J., Memorandum of Prof. A.K. Oppenheim and an Example of Application of the Oppenheim Correlation (OPC) for the Heat Losses During the Combustion in IC-Engine, Journal of KONES 2010 Powertrain and Transport, Vol. 17 No. 2, pp. 181 194, Warsaw 2010.

[4] Jankowski, A., Heat Transfer in Combustion Chamber of Piston Engines, Journal of KONES Powertrain and Transport, Vol. 17, No. 1, pp. 187-197, Warsaw 2010.

[5] Jankowski, A., Kruczynski, S. S., Novel Catalytic Converter Oxide for SI Engines, Journal of KONES Powertrain and Transport, Vol. 17, No. 1, pp. 177-186, Warsaw 2010.

[6] Jankowski, A., Laser research of fuel atomization and combustion processes in the aspect of exhaust gases emission, Journal of KONES Internal Combustion Engines, Vol. 15, No. 1, pp. 119-126, Warsaw 2008.

[7] Jankowski, A., Laser research of fuel atomization and combustion processes in the aspect of exhaust gases emission, Journal of KONES Internal Combustion Engines, Vol. 15, No. 1, pp. 119-126, Warsaw 2008.

[8] Jankowski, A., Reduction Emission Level of Harmful Components Exhaust Gases by Means of Control of Parameters Influencing on Spraying Process of Biofuel Components for Aircraft Engines, Journal of KONES Powertrain and Transport, Vol. 18, No. 3, pp. 129-134, Warsaw 2011.

[9] Jankowski, A., Sandel, A., Exhaust Emission Reduction Problems of Internal Combustion Engines Fueled With Biofuels, Journal of KONES Internal Combustion Engines 2003, Vol. 10, No. 3-4, Warsaw 2003.

[10] Jankowski, A., Sandel, A., Influence of Fuel Quality on Mixture Preparation and Exhaust Emissions from Diesel Engines with Common Rail System, Journal of KONES Internal Combustion Engines 2003, Vol. 10, No. 3-4, Warsaw 2003.

[11] Jankowski, A., Sandel, A., Jankowska-Siemińska, B., Sęczyk, J., Measurement of drop size distribution in fuel sprays by laser methods, Journal of KONES, 2001, Vol. 8, No. 3-4, pp. 334-345, Warsaw 2002.

[12] Jankowski, A., Sandel, A., Sęczyk, J., Siemińska-Jankowska, B., Some Problems of Improvement of Fuel Efficiency and Emissions in Internal Combustion Engines, Journal of KONES Internal Combustion Engines 2002, Vol. 9, No. 3-4, pp. 333-356, Warsaw 2002.

[13] Jankowski, A., Some Aspects of Heterogeneous Processes of the Combustion Including Two Phases, Journal of KONES Internal Combustion Engines, Vol. 12, No. 1-2, pp. 121-134, Warsaw 2005.

[14] Jankowski, A., Studium wpływu ciśnienia, prędkości i rodzaju strugi gazów na przebieg procesu spalania, Prace Naukowe Instytutu Technicznego Wojsk Lotniczych, Zeszyt Nr 28, Warszawa 2010.

[15] Jankowski, A., Study of the influence of different factors on combustion processes (Part two), Journal of KONES Internal Combustion Engines, Vol. 16, No. 3, pp. 135-140, Warsaw 2009. 